\title{
Isolation and antioxidant activity of 5-methyldihydroflavasperone from ethanol leaf extract of Guiera senegalensis JF Gmel
}

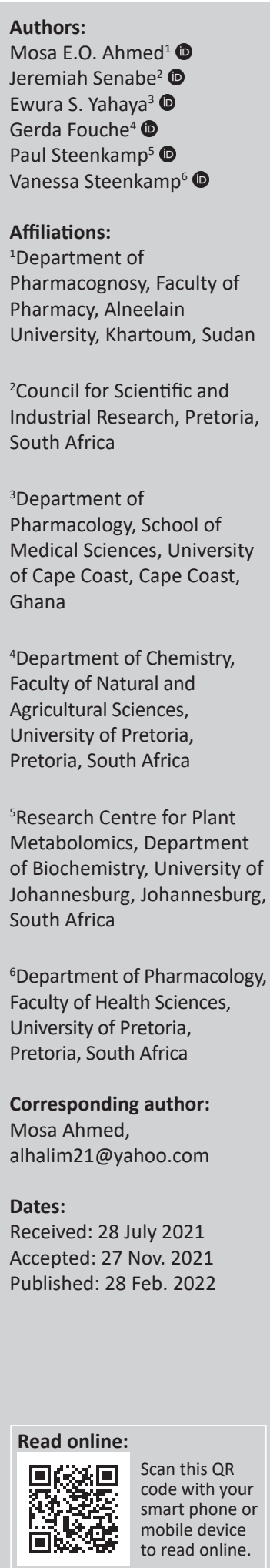

Background: Guiera senegalensis (Ghibaish) is a medicinal plant extensively used in central and west Africa for the management of various diseases.

Aim: This study aimed to determine the antioxidant activity of the ethanol leaf extract of the plant.

Method: The ethanol leaf extract was sequentially sub-fractionated using liquid-liquid extraction, vacuum-liquid chromatography and preparative thin layer chromatography. Ultraperformance liquid chromatography with accurate mass spectrometry and nuclear magnetic resonance were employed to isolate and confirm the identity of the most abundant compound. The antioxidant activity of the fractions and isolated compound was assessed by bioautography analysis and the 2,2-diphenyl-1-picrylhydrazyl hydrate (DPPH) radical scavenging assay.

Results: The dichloromethane subfraction contained the most promising antioxidant activity $\left(\mathrm{IC}_{50}=3.18 \mu \mathrm{g} / \mathrm{mL}\right)$. Purification of this subfraction led to the isolation of a brown crystalline compound, which was identified as 5-methyldihydroflavasperone $\left(\mathrm{IC}_{50}>4000 \mu \mathrm{g} / \mathrm{mL}\right)$.

Conclusion: This is the first report of the isolation of 5-methyldihydroflavasperone from the ethanol leaf extracts of $G$. senegalensis. This compound was not found to be responsible for the antioxidant activity observed. Further research is warranted to identify the compound responsible for the antioxidant activity.

Keywords: Antioxidant activity; DPPH assay; Guiera senegalensis; 5-methyldihydroflavasperone; NMR spectroscopy; UPLC-MS analysis.

\section{Introduction}

Traditional medicine remains an important aspect of health care globally, and is widely used in the treatment and prevention of diseases (Li \& Weng 2017). Furthermore, it serves as a promising source of phytochemical compounds used for the development of conventional medications (Yuan et al. 2016). In Africa and other developing countries, most people rely on herbal medications for primary healthcare (Malami et al. 2020). Guiera senegalensis (Combretaceae) is a medicinal plant that is widely distributed in the savannah regions of west and central African countries, such as Nigeria, Senegal, Gambia, Mali, Niger, Burkina Faso and Ghana (Salihu \& Usman 2015). In Sudan, where it is locally known as 'Ghibaish', the leaves are used for leprosy prevention, whilst a root decoction is used for the treatment of diarrhoea and dysentery (Mariod, Matthäus \& Hussein 2006). A herbal tea prepared from the plant is used to treat malaria, severe diarrhoea, dysentery, eczema, chest conditions and cold (Ifijen et al. 2019; Somboro et al. 2011).

Several compounds have been isolated from the leaves of G. senegalensis; the naphthopyran, 5-methylflavasperone (5,8,10-trimethoxy-2-methyl-4-H-naphtho[1,2-b]pyran-4-one); rhamnetin from the methylene chloride extract (Bucar et al. 1998) and 5-methyldihydroflavasperone (2,3-dihydro-5,8,10-trimethoxy-2-methyl-4H-naphtho[1,2-b]pyran-4-one) (Figure 1) from the chloroform extract (Mahmoud \& Khalid 1997). Both 5-methylflavasperone and rhamnetin are reported to induce inhibitory effects on 5-lipoxygenase and the hydroxyl radical (Bucar et al. 1998). Other identified compounds include guieranone A, an antifungal compound, and the indole alkaloids: harman, harmalan and tetrahydroharman (Fiot et al. 2006; Silva \& Gomes 2003).

How to cite this article: Ahmed, M.E.O., Senabe, J., Yahaya, E.S., Fouche, G., Steenkamp, P. \& Steenkamp, V., 2022, 'Isolation and antioxidant activity of 5-methyldihydroflavasperone from ethanol leaf extract of Guiera senegalensis JF Gmel', Journal of Medicinal Plants for Economic Development 6(1), a137. https://doi.org/10.4102/jomped.v6i1.137

Copyright: ( 2022. The Authors. Licensee: AOSIS. This work is licensed under the Creative Commons Attribution License. 


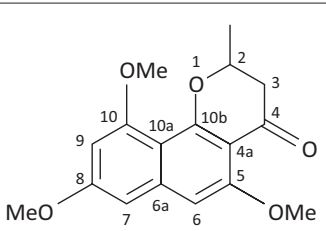

FIGURE 1: Chemical structure of 5-methyldihydroflavasperone.

To add to the knowledge pool on G. senegalensis, this study aimed to determine the antioxidant activity of the ethanol leaf extract of the plant.

\section{Materials and methods Chemicals and solvents}

All chemicals, solvents and reagents used are of analytical grade. The 2,2-diphenyl-1-picrylhydrazyl hydrate (DPPH) radical reagent was purchased from Sigma-Aldrich (Germany). Ascorbic acid was purchased from Merck chemicals (PTY) Ltd (SA). Aluminium-coated plates (silica gel 60 F254; $0.25 \mathrm{~mm}$, $20 \mathrm{~cm} \times 20 \mathrm{~cm}$ ) were purchased from Merck (Germany) and preparative silica gel plates (silica gel $60 \mathrm{~F} 254 ; 2 \mathrm{~mm}, 20 \mathrm{~cm} \times$ $20 \mathrm{~cm}$ ) from Anatech (USA). All the solvents used for mass spectrometric analysis were of the highest purity and procured from Honeywell (Muskegon, USA).

\section{Sample collection and preparation}

Guiera senegalensis J.F. Gmel. leaves were collected from Northern Kurdufan state in Sudan in October 2015. The specimen was authenticated by Dr Yahiya Suleiman of the Medicinal and Aromatic Plants Research Institute, Sudan (MAPRI) wherea voucherspecimen(W-1997-21-MAPTMRI-H) is deposited.

\section{Sample preparation}

Collected leaves $(2 \mathrm{~kg}$ ) were dried in the shade, after which they were macerated and extracted twice with $96 \%$ ethanol (10.35 L) for $72 \mathrm{~h}$. The obtained extract was filtered under gravity and concentrated using a rotary evaporator (Laborota 4000-Efficient, Heidolph, Germany). The filtrate (135.9 g) was dried in vacuo, resulting in a solid marc, which was green or black in colour. The latter was stored in an airtight bottle at $2^{\circ} \mathrm{C}$ until analyses were carried out.

\section{Sample extraction}

Fractionation was achieved by dissolving the ethanol extract $(135.9 \mathrm{~g})$ in chloroform $(750 \mathrm{~mL})$ and mixing with distilled water $(450 \mathrm{~mL})$. The chloroform fraction was partitioned between hexane $(1.85 \mathrm{~L})$ and $90 \%$ methanol:water $(700 \mathrm{~mL})$. The resultant fraction was diluted with distilled water $(200 \mathrm{~mL})$ and extracted with dichloromethane (900 mL) (Ayoub \& Kingston 1984). All the fractions were evaporated, air-dried and kept in sealed containers, which were stored at $2^{\circ} \mathrm{C}$ until use (Figure 2).

All subfractions were monitored for antioxidant activity in order to identify the most active subfraction, which was

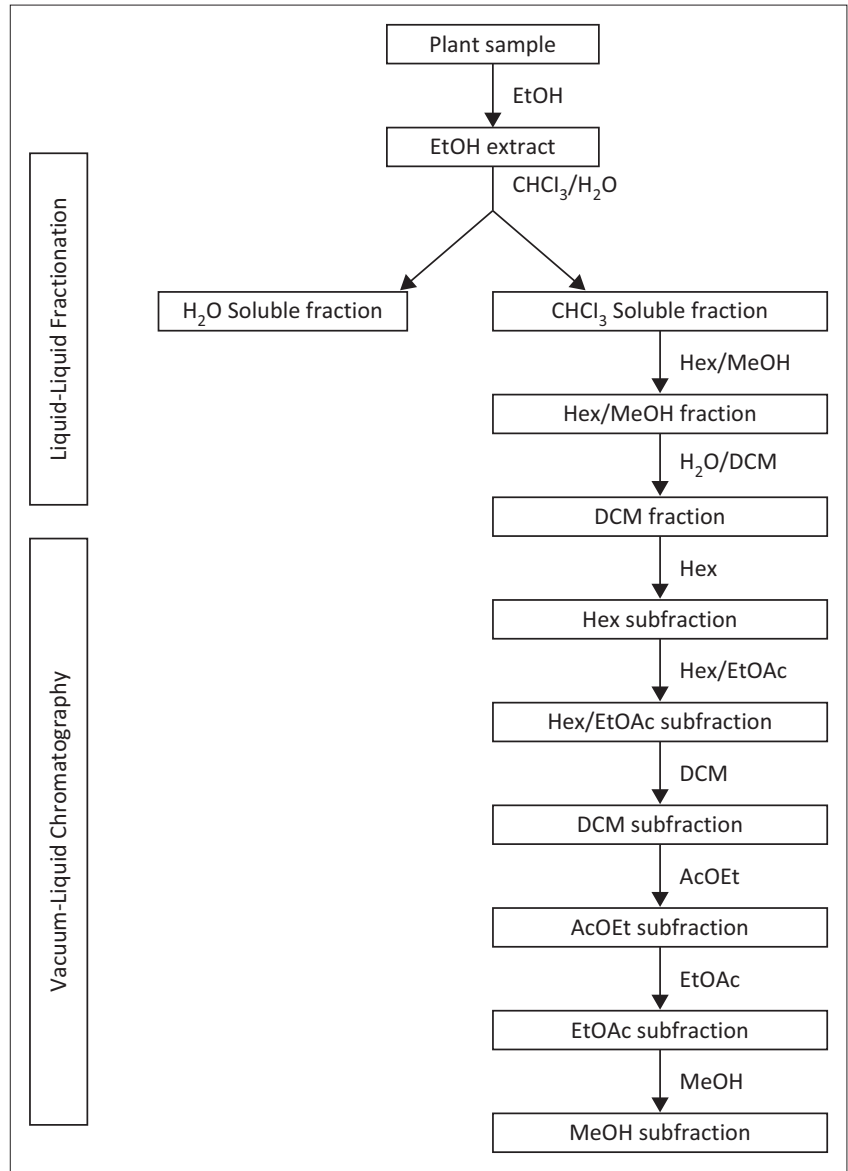

FIGURE 2: Schematic presentation summarising the extract preparation and purification of the fractions. AcOEt, acetone; DCM, dichloromethane; EtOAc, ethyl acetate; EtOH, ethanol; $\mathrm{CHCl}_{3}$, chloroform; $\mathrm{H}_{2} \mathrm{O}$, water; Hex, hexane; $\mathrm{MeOH}$, methanol.

subjected to further purification (as described in the following section).

\section{Purification of subfraction with highest activity}

The dichloromethane soluble fraction $(56.95 \mathrm{~g})$ was further purified by vacuum-liquid chromatography with silica gel as the stationary phase. An aliquot (346 g) was loaded onto the silica gel column and sequentially eluted with hexane $(6 \mathrm{~L})$, hexane: ethyl acetate $(4: 6 ; 3.5 \mathrm{~L})$, dichloromethane $(1.7 \mathrm{~L})$, acetone $(3 \mathrm{~L})$, ethyl acetate $(1.25 \mathrm{~L})$ and methanol $(4.65 \mathrm{~L})$.

The dichloromethane subfraction (0.45 g) was subjected to further purification on preparative thin layer chromatography (TLC) and visualisation occurred as described here. Ten bands were detected. Band number $4\left(\mathrm{R}_{\mathrm{f}}=0.41\right.$, yellow or green colour under normal light, green colour under ultraviolet [UV] light) was removed by scraping and dissolved in dichloromethane. The new subfraction was filtered and then loaded onto a preparative TLC plate $(3 \mathrm{~mL})$. The mobile phase used for development consisted of toluene:ethyl acetate:formic acid (6:3.5:0.5). This afforded the detection of 15 bands when visualised using both normal and UV light. Of the 15 bands, the seventh band $\left(R_{\mathrm{f}}=0.59\right.$, deep yellow colour $)$ was removed by scraping it off, after which it was dissolved in dichloromethane. The fraction was filtered and eluted with toluene:ethyl acetate:formic acid (3:6.9:0.1). After subjection to 
elution using TLC (silica gel GF, $2 \mathrm{~mm}$ ) and visualisation using normal and UV light, 13 bands were obtained. From the latter, the 5 th band $\left(\mathrm{R}_{\mathrm{f}}=0.62\right.$, deep yellow colour) was scraped off and dissolved in dichloromethane, filtered and dried. This yielded brown crystals, which were subjected to further analysis to determine compound identity.

\section{Structure elucidation of the isolated compound}

Structure elucidation of the compound was carried out using ${ }^{1} \mathrm{H}-\mathrm{NMR}$ and ${ }^{13} \mathrm{C}-\mathrm{NMR}$ on a $600 \mathrm{MHz}$ Varian NMR instrument (Varian Inc., USA).

The molecular mass was determined using a Waters Acquity Classic UPLC System coupled to a Waters Synapt G1 HDMS mass spectrometer (Waters, UK). Mass spectrometric (MS) analysis was carried out in full-scan mode in both ionisation modes. A Waters Classic binary Ultra-performance liquid chromatography (UPLC) system, coupled in series to a Waters SYNAPT G1 HDMS mass spectrometer was used to generate full scan and MS/MS accurate mass data. Optimisation of the chromatographic separation was carried out utilising a Waters HSS T3 C18 column $(150 \mathrm{~mm} \times 2.1 \mathrm{~mm}, 1.8 \mu \mathrm{m})$ and the column temperature was maintained at $60^{\circ} \mathrm{C}$. A binary solvent mixture was used consisting of water (Eluent A), which contained $10 \mathrm{mM}$ formic acid (natural $\mathrm{pH}$ of 2.4) and acetonitrile (Eluent B) containing $10 \mathrm{mM}$ formic acid. The initial conditions were $80 \% \mathrm{~A}$ at a flow rate of $0.4 \mathrm{~mL} / \mathrm{min}$ and were maintained for $1 \mathrm{~min}$, followed by a gradient increase to $5 \% \mathrm{~A}$ at $16 \mathrm{~min}$. The conditions were kept constant for $1 \mathrm{~min}$ and then changed to the initial conditions. The total runtime was $20 \mathrm{~min}$ and the injection volume was $2 \mu \mathrm{L}$. Samples were maintained at $6^{\circ} \mathrm{C}$ in the Waters Sample Manager during analysis.

A SYNAPT G1 mass spectrometer was used in V-optics configuration and operated in electrospray mode to enable detection of all electrospray ionisation (ESI)-compatible compounds. Leucine enkephalin $(50 \mathrm{pg} / \mathrm{mL})$ was used as a reference calibrant (Lock Mass) to obtain typical mass accuracies between $1 \mathrm{mDa}$ and $5 \mathrm{mDa}$. The mass spectrometer was operated in both ESI-positive and -negative modes, with a capillary voltage of $2.5 \mathrm{kV}$, the sampling cone at $30 \mathrm{~V}$ and the extraction cone at $4.5 \mathrm{~V}$. The scan time was $0.1 \mathrm{~s}$ covering the $50 \mathrm{Da}$ to $1000 \mathrm{Da}$ mass range with an interscan time of $0.02 \mathrm{~s}$. The source temperature was set at $120^{\circ} \mathrm{C}$ and the desolvation temperature at $450^{\circ} \mathrm{C}$. Nitrogen was used as the nebulisation gas at a flow rate of $550 \mathrm{~L} / \mathrm{h}$, and cone gas was added at $50 \mathrm{~L} / \mathrm{h}$. Argon was used as collision gas in the collision cell during fragmentation experiments. The software used to control the hyphenated system and do all data manipulation was MassLynx 4.1 (SCN 872). Compound identification was further enhanced by analysing all samples with low and high collision energy settings of the collision cell. To minimise compound fragmentation a low-energy setting of $3 \mathrm{~V}$ was used, but to enhance fragmentation of molecules, five different collision energy profiles between $10 \mathrm{~V}$ and $50 \mathrm{~V}$ were used (MSe).

\section{Antioxidant activity}

\section{Bioautography}

The subfractions were dissolved in the respective solvent of extraction and loaded as spots onto the TLC plates (silica gel $60 \mathrm{~F}_{254^{\prime}} 0.25 \mathrm{~mm}$ thickness). The plates were placed in a saturated development chamber with a mobile phase consisting of toluene: ethyl acetate: formic acid (5:4:1). The plates were removed and air-dried when the solvent front was $1 \mathrm{~cm}$ from the top.

After development, plates were sprayed with vanillin sulphuric acid and visualised under normal and UV light (254 nm and $365 \mathrm{~nm}$, respectively) (Model NU-8 KL, Benda, Germany). The presence of any fluorescent or quenching compounds was observed as white or yellow spots against a purple background (Gu, Wu \& Wang 2009).

\section{2,2-diphenyl-1-picrylhydrazyl hydrate radical radical scavenging assay}

The DPPH radical scavenging activity was determined using the method described by Brand-Williams, Cuvelier and Berset (1995) with minor modification. The reduction of DPPH by the antioxidant compound results in a change in colour from deep violet to yellow. An aliquot of $100 \mu \mathrm{L}$ DPPH $(0.135 \mathrm{mM}$ in methanol) was added to varying concentrations of the extracts $(3 \mu \mathrm{g} / \mathrm{mL}-100 \mu \mathrm{g} / \mathrm{mL} ; 100 \mu \mathrm{L})$ or the positive control, ascorbic acid $(1 \mathrm{mM})$ in a 96-well plate. The mixture was incubated in the dark for $30 \mathrm{~min}$ at room temperature, and the absorbance was measured using a spectrophotometer (BioTek Synergy 2, BioTek instruments, USA) set at an absorbance wavelength of $515 \mathrm{~nm}$. The ability of extracts to scavenge the DPPH radical was calculated using the following equation:

DPPH radical scavenging activity

$(\%$ relative to negative control $)=\left[\frac{\mathrm{A} \text { control }-\mathrm{A} \text { sample }}{\mathrm{A} \text { control }}\right] \times 100$

[Eqn 1]

where $\mathrm{A}_{\text {control }}$ is the absorbance of DPPH radical + methanol and $\mathrm{A}_{\text {sample }}$ is the absorbance of DPPH radical + extract or standard. The $\mathrm{IC}_{50}$ for each extract was calculated using computer software (Graph Pad prism 7, Graphpad Software Inc., USA). The assays were conducted in triplicate on three different occasions.

\section{Ethical considerations}

This study followed all ethical standards for research without direct contact with human or animal subjects.

\section{Results and discussion}

\section{Fractionation and purification of the extract}

Fractionation of the ethanol leaf extract using liquid-liquid extraction resulted in four fractions: water soluble fraction (gummy brown; yield 23.50\%), hexane soluble fraction (oily/green; yield 5.61\%), methanol:water (8:1) soluble fraction (gummy/brown; yield $14.40 \%$ ) and dichloromethane 

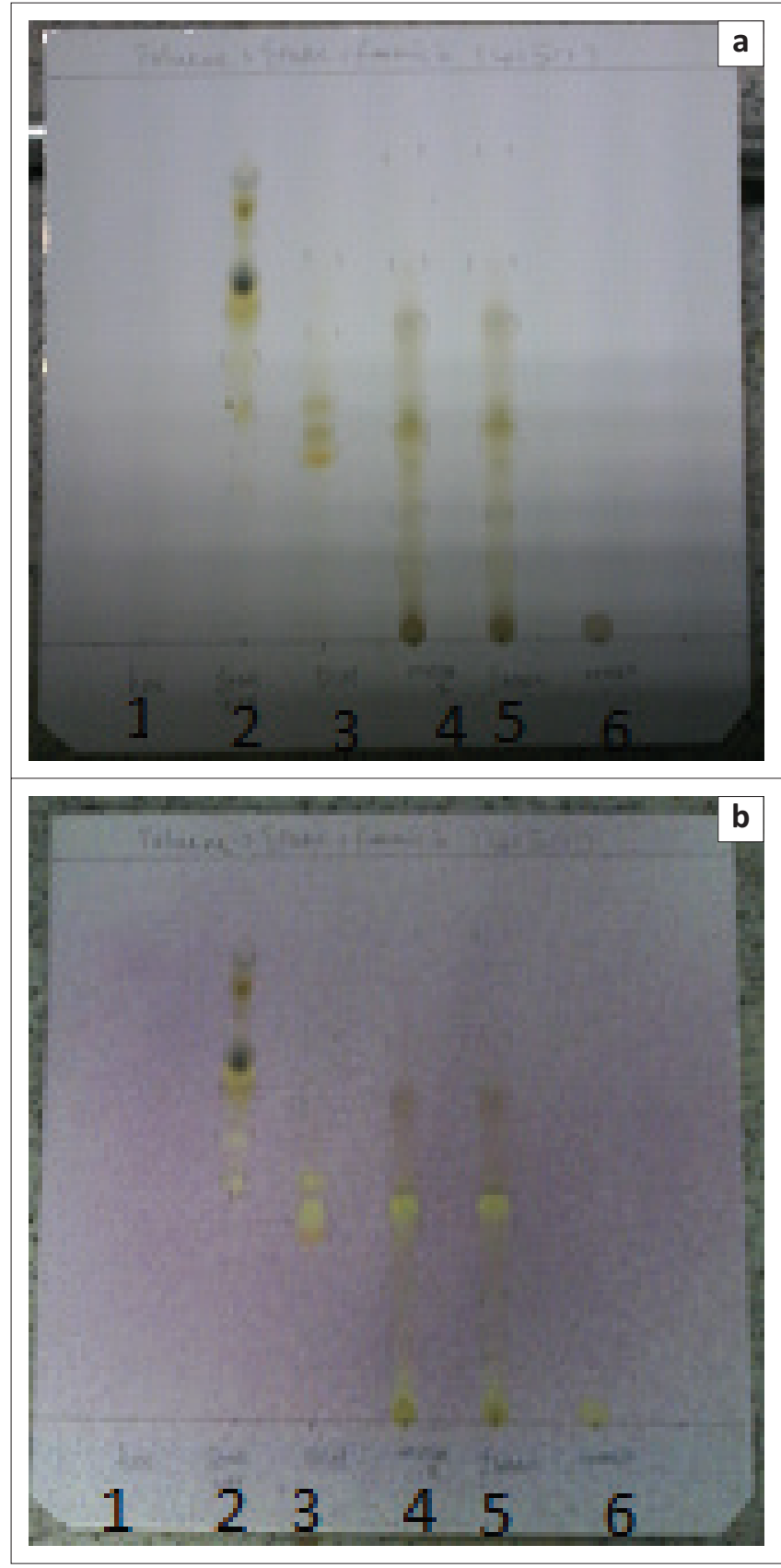

FIGURE 3: Bioautography analysis of subfractions of the dichloromethane fraction using (a) normal light and (b) UV light. Lane 1: hexane (oily/yellow), lane 2: ethyl acetate:hexane (4:6) (oily/green), lane 3: dichloromethane (solid/ brown), lane 4: acetone (solid/green), lane 5: ethyl acetate (solid/green), lane 6: methanol (solid/brown).

soluble fraction (amorphous/green; yield 45.10\%). As the dichloromethane fraction had the highest yield, it was subjected to further purification using a vacuum column resulting in six subfractions. As shown in Figure 3, the six subfractions of the dichloromethane fraction were spotted onto a TLC plate (silica gel $60 \mathrm{~F}_{254^{\prime}} 0.25 \mathrm{~mm}$ thickness) for bioautography analysis. These chromatograms were visualised under normal light (plate A) and $\mathrm{UV}_{254}$ light (plate B). All subfractions indicated the same number of spots when visualised using either light options. The sixth subfraction (methanol) was the only subfraction that was devoid of yellow florescent spots when visualised under $\mathrm{UV}_{254}$ light.
TABLE 1: ${ }^{1} \mathrm{H}-\mathrm{NMR}$ spectral data $\left(600 \mathrm{MHz}, \mathrm{CDCl}_{3}\right)$ of the subfraction $(4 / 7 / 5)$ and 5-methyldihdroflavasperone.

\begin{tabular}{lcccl}
\hline Assignment & Position (ppm) & $\begin{array}{c}\text { Position (ppm) } \\
\text { (El Hadi \& } \\
\text { Khalid 1997) }\end{array}$ & Integration & Multiplicity \\
\hline $2-\mathrm{CH}-$ & 4.64 & $4.7(\mathrm{~m})$ & $1 \mathrm{H}$ & Multiplet \\
$2-\mathrm{CH} 3$ & 1.57 & $1.6(\mathrm{~d})$ & $3 \mathrm{H}$ & Doublet \\
$3-\mathrm{CH} 2$ & 2.69 & $2.7(\mathrm{~m})$ & $2 \mathrm{H}$ & Multiplet \\
$5-\mathrm{OCH} 3$ & 3.94 & $3.96(\mathrm{~s})$ & $3 \mathrm{H}$ & Singlet \\
$6-\mathrm{CH}$ & 6.54 & $6.52(\mathrm{~s})$ & $1 \mathrm{H}$ & Singlet \\
$7-\mathrm{CH}$ & 6.52 & $6.49(\mathrm{~d})$ & $1 \mathrm{H}$ & Doublet \\
$8-\mathrm{OCH} 3$ & 3.88 & $3.9(\mathrm{~s})$ & $3 \mathrm{H}$ & Singlet \\
$9-\mathrm{CH}$ & 6.32 & $6.3(\mathrm{~d})$ & $1 \mathrm{H}$ & Doublet \\
$10-\mathrm{OCH} 3$ & 3.89 & $3.92(\mathrm{~s})$ & $3 \mathrm{H}$ & Singlet \\
\hline & & & &
\end{tabular}

TABLE 2: Comparison between ${ }^{13} \mathrm{C}-\mathrm{NMR}$ spectral data $\left(600 \mathrm{MHz}, \mathrm{CDCl}_{3}\right)$ of the subfraction (4/7/5) and 5-methyl-dihdroflavasperone.

\begin{tabular}{lcc}
\hline Assignment & Position (ppm) & $\begin{array}{c}\text { Position (ppm) } \\
\text { (El Hadi \& Khalid 1997) }\end{array}$ \\
\hline 2-CH & 74.9 & 74.6 \\
2-CH3 & 20.9 & 20.6 \\
3-CH2 & 45.6 & 45.3 \\
4-C=O & 191.0 & 190.6 \\
4a-C=C- & 108.5 & 108.1 \\
5-C=C- & 157.9 & 157.6 \\
5-OCH3 & 56.0 & 55.7 \\
6-C=C- & 99.3 & 98.9 \\
6a-C=C- & 141.7 & 141.4 \\
7-C=C- & 98.6 & 98.4 \\
8-C=C- & 161.8 & 161.5 \\
8-OCH3 & 55.6 & 55.2 \\
9-C=C- & 97.5 & 97.2 \\
10-C=C- & 160.4 & 160.1 \\
10-OCH3 & 56.2 & 55.8 \\
10a-C=C- & 107.6 & 107.3 \\
10b-C=C- & 164.3 & 164.0 \\
\hline
\end{tabular}

\section{Structure elucidation of isolated compound}

\section{${ }^{1} \mathrm{H}$ - and ${ }^{13} \mathrm{C}-\mathrm{NMR}$ analysis}

The ${ }^{1} \mathrm{H}-\mathrm{NMR}$ spectrum showed a doublet at $\delta 1.57$ indicative of a methyl group, a multiplet at $\delta 2.69$ indicative of a methylene group, and three singlets at $\delta 3.94,3.88$ and 3.89 related to three methoxyl groups at C-5, C-8 and C-10, respectively, with the multiplet at $\delta 4.64$ attributed to one proton (Table 1 and Figure 4 ). The aromatic region showed two doublets at $\delta 6.32$ and 6.52 and a singlet at $\delta$ 6.54. This finding is consistent with that of an earlier study on the chloroform extract of the plant where 5-methyl-dihydroflavasperone (2,3-dihydro-5,8,10-trimethoxy2-methyl-4H-naphtho [1,2-b] pyran-4-one) was identified (El Hadi \& Khalid 1997).

The ${ }^{13} \mathrm{C}$-NMR spectral data indicated 17 carbon atoms and showed a chemical shift at $\delta 191.0$, which is indicative of a carbonyl carbon (Table 2 and Figure 5). ${ }^{13} \mathrm{C}-\mathrm{NMR}$ analysis also indicated the presence of a methyl group $(\delta$ 20.9), three methoxyl groups $(\delta 56.0,55.6$ and 56.2), one methylene $(\delta 45.6)$ and one ethyl group at $\delta$ 74.9. Three aromatic carbons were also observed at $\delta 98.6,97.5$ (ring b) and 99.3 (ring a). A similar finding has been reported for 5-methyldihydroflavasperone (El Hadi \& Khalid 1997). 


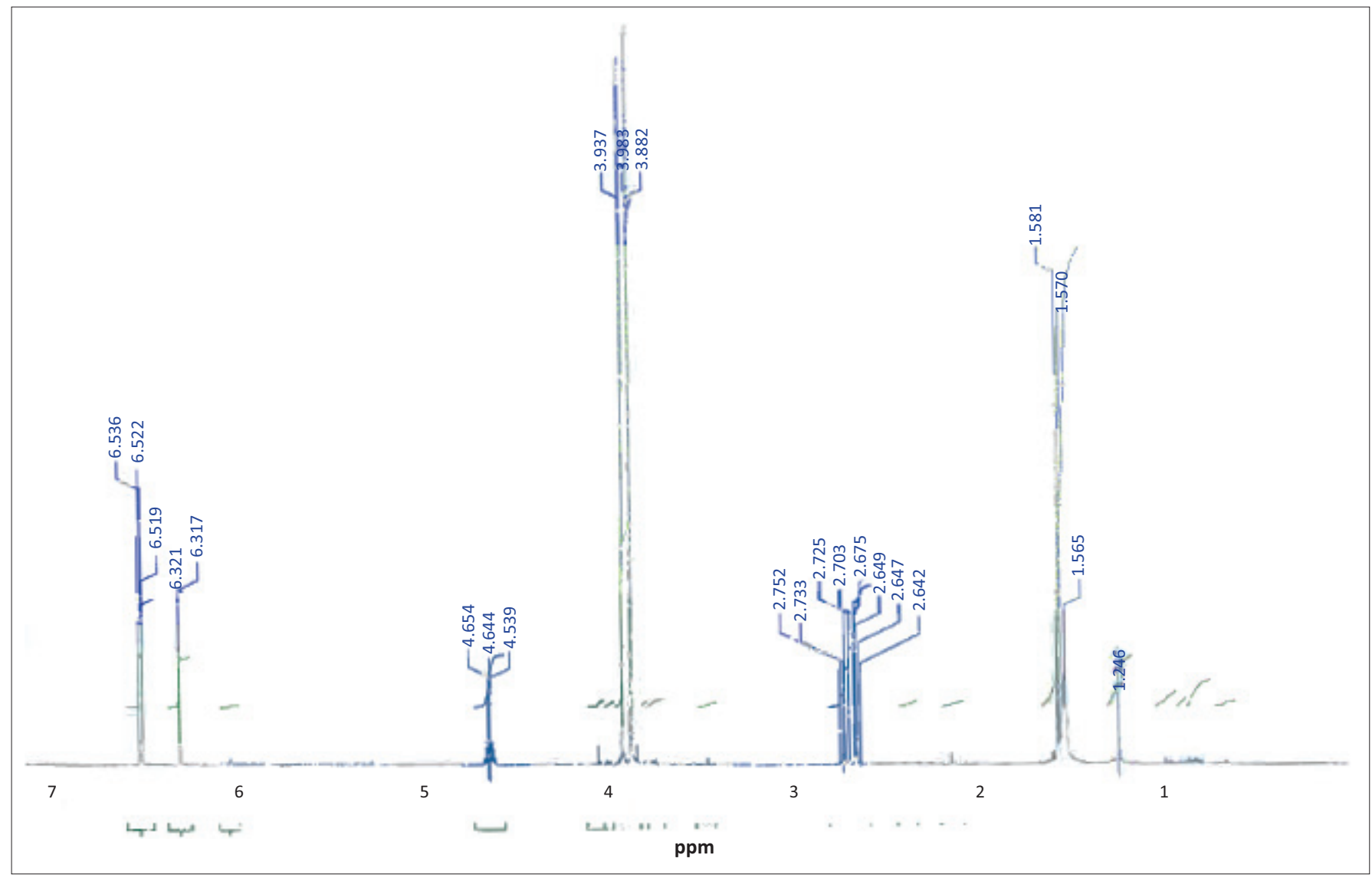

FIGURE 4: ${ }^{1} 1 \mathrm{H}-\mathrm{NMR}$ spectral data $(600 \mathrm{MHz}, \mathrm{CDCl} 3)$ of sub-fractions of the dichloromethane fraction of $G$. senegalensis showing a doublet at $\delta 1.57$, a multiplet at $\delta 2.69$, three singlets at $\delta 3.94-3.89$, and a multiplet at $\delta 4.64$.

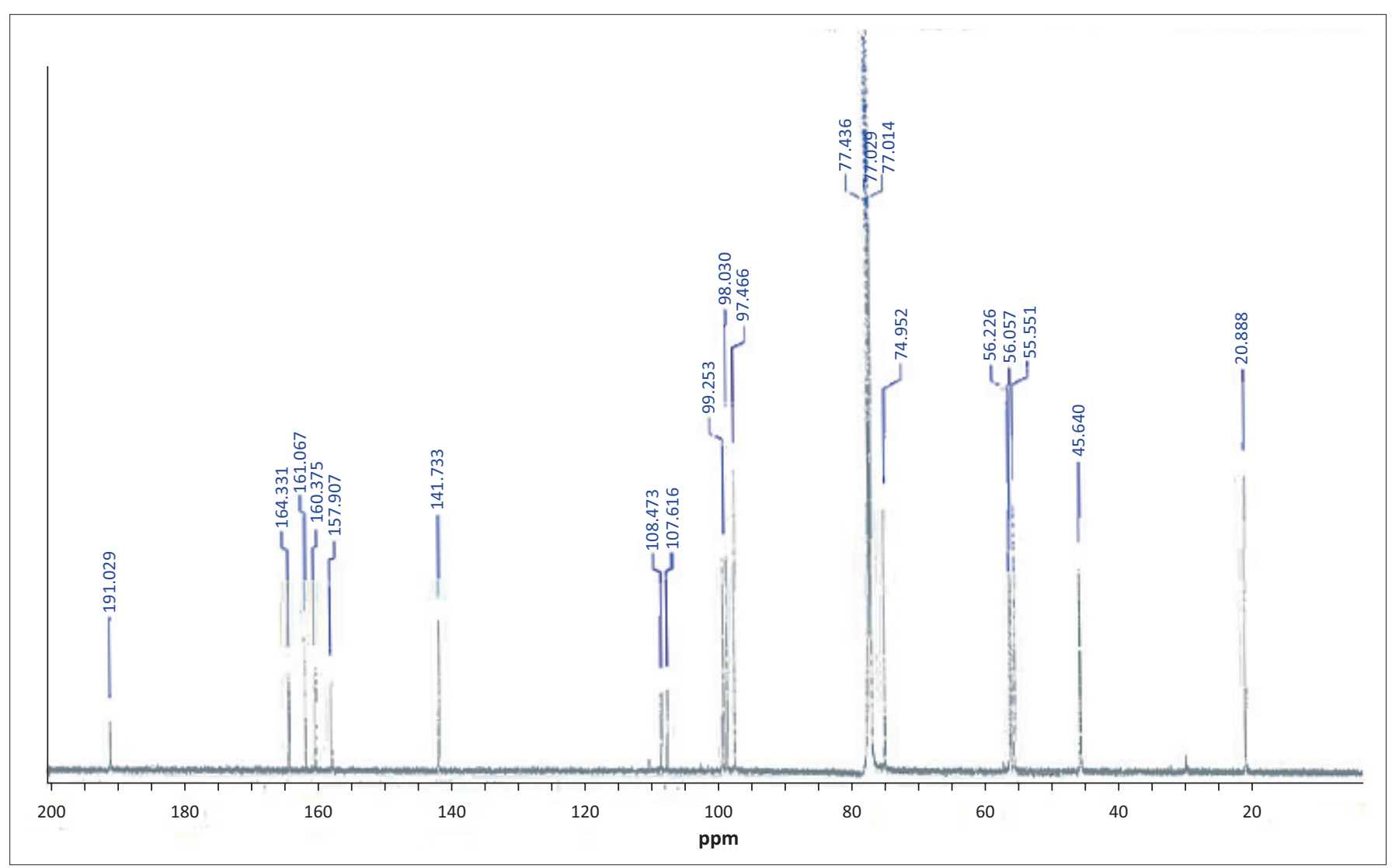

FIGURE 5: ${ }^{13} \mathrm{C}-\mathrm{NMR}$ spectral data $(600 \mathrm{MHz}, \mathrm{CDCl} 3)$ of sub-fractions of the dichloromethane fraction of $\mathrm{G}$. senegalensis showing 17 carbons. 


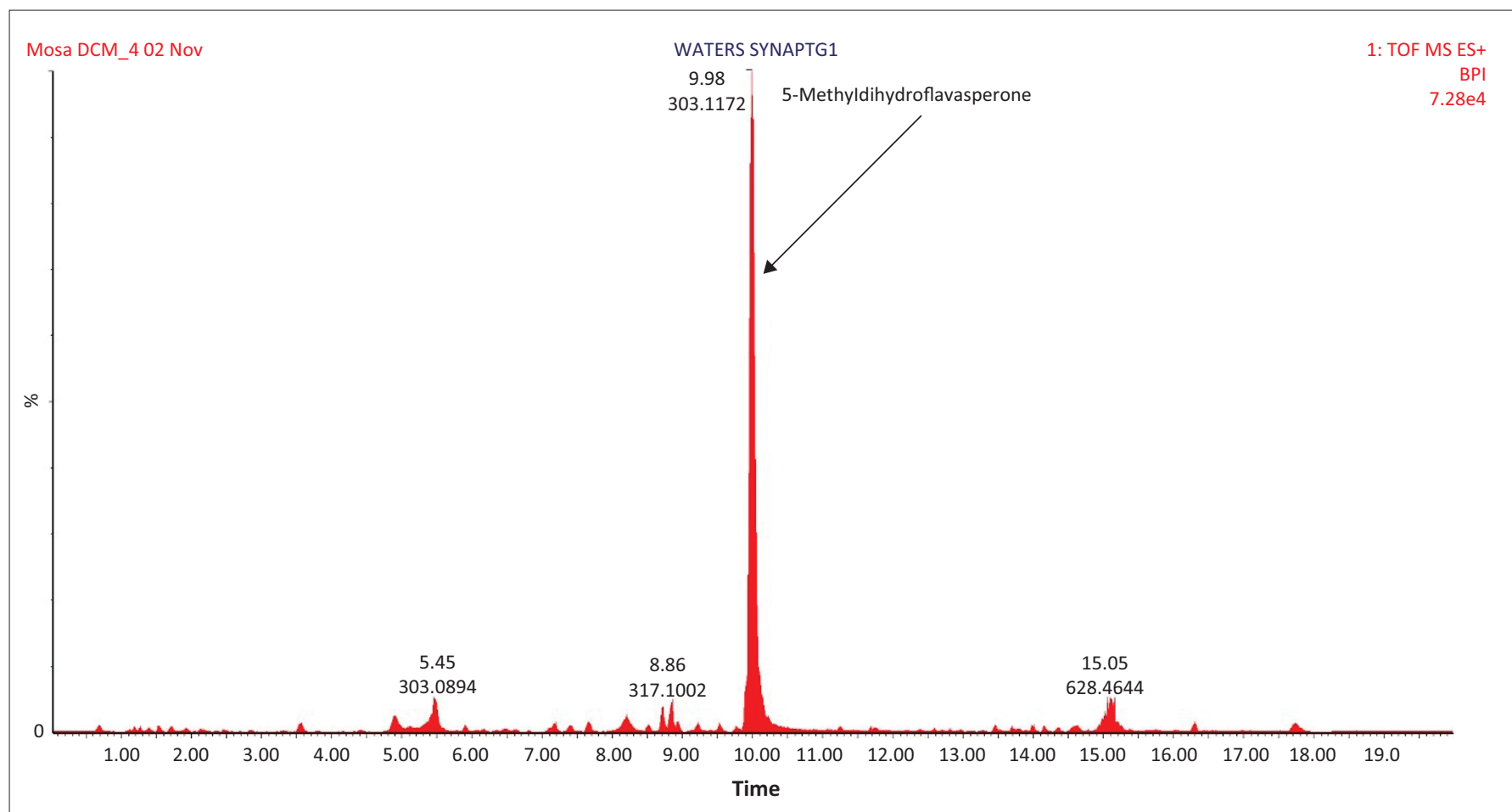

FIGURE 6: Ultra-performance liquid chromatography Time-of-Flight positive electrospray base peak intensity (UPLC TOF ESI ${ }^{+}$BPI) chromatogram of the subfraction (4/7/5) with the highest antioxidant activity.

\section{UPLC-MS analysis}

The molecular mass was determined using a Waters Acquity Classic UPLC System coupled to a Waters Synapt G1 HDMS mass spectrometer (Waters, UK). MS analysis was carried out in full-scan mode in both ionisation modes. The leading compound was detected in positive ionisation mode with precursor $[\mathrm{M}+\mathrm{H}]^{+}$ $m / z 303.1237$ and elemental composition $\mathrm{C}_{17} \mathrm{H}_{19} \mathrm{O}_{5}$ and a double bond equivalent (DBE) count of 9 . The theoretical calculation of $\mathrm{C}_{17} \mathrm{H}_{18} \mathrm{O}_{5}, \mathrm{~m} / \mathrm{z} 302.1154$ indicated a mass accuracy of $0.5 \mathrm{mDa}$, and the isotope ratio was 0.00 (perfect score).

MSe analysis resulted in five product ions, namely $\left[\mathrm{M}+\mathrm{H}-\mathrm{CH}_{3}\right]^{+}$, $m / z$ 288.0990; $\left[\mathrm{M}+\mathrm{H}-\mathrm{C}_{2} \mathrm{H} 6\right]^{+}, \mathrm{m} / z$ 273.0760; $\left[\mathrm{M}+\mathrm{H}-\mathrm{C}_{3} \mathrm{H}_{9}\right]^{+}, \mathrm{m} / z$ 258.0518; $\left[\mathrm{M}+\mathrm{H}-\mathrm{C}_{4} \mathrm{H}_{8}\right]^{+}, m / z 247.0604$ and $\left[\mathrm{M}+\mathrm{H}-\mathrm{C}_{5} \mathrm{H}_{9} \mathrm{O}\right]^{+}, \mathrm{m} / \mathrm{z}$ 218.0564. The results were confirmed by MassFragment analysis. MassFragment software automatically identifies product ion fragments using a series of novel, chemically intelligent algorithms. This approach is based on systematic bond disconnection of the precursor structure instead of the traditional rule-based approach, which is limited to the extent that the rules are coded and will not always provide the information required.

The MS spectral data of the subfraction $(4 / 7 / 5)$ are provided in Figure 6. Elemental analysis of the compound was calculated as $\mathrm{C}_{17} \mathrm{H}_{18} \mathrm{O}_{5}$, which corresponds to an earlier study on the chloroform extract of the plant (El Hadi \& Khalid 1997).

\section{Antioxidant activity}

The dichloromethane subfraction exhibited the highest antioxidant activity $(3.18 \mu \mathrm{g} / \mathrm{mL})$ (Table 3$)$, which was 30\% higher than that of the standard antioxidant, ascorbic acid. Previous studies have reported the antioxidant activity of
TABLE 3: The $\mathrm{IC}_{50}$ of ethanol extract, dichloromethane fraction, dichloromethane subfractions and ascorbic acid (standard) as determined using the 2,2-diphenyl1-picrylhydrazyl hydrate radical assay.

\begin{tabular}{lc}
\hline Extracts/fractions/sub-fractions & $\mathrm{IC}_{50}(\mu \mathrm{g} / \mathrm{mL})$ \\
\hline $96 \%$ ethanol extract & $10.21 \pm 0.07$ \\
Dichloromethane soluble fraction & $4.73 \pm 0.10$ \\
Hexane subfraction & $>150$ \\
$40 \%$ ethyl acetate: hexane subfraction & $>150$ \\
Dichloromethane subfraction & $3.18 \pm 0.06$ \\
Acetone subfraction & $7.19 \pm 0.07$ \\
Ethyl acetate subfraction & $16.42 \pm 0.08$ \\
Methanol subfraction & $5.54 \pm 0.06$ \\
5-Methyldihydroflavasperone & $>4000$ \\
Standard & \\
Ascorbic acid & $4.65 \pm 0.23$ \\
\hline
\end{tabular}

extracts prepared from various parts of the plant. The antioxidant potential of aqueous extracts prepared from the roots, stems and leaves is known (Atawodi \& Onaolapo 2010). Other studies on the ethanol and methanol extracts of the plant also reported similar findings. As reported by Adebayo et al. (2019), the $\mathrm{IC}_{50}$ of methanol extract for the bark of G. senegalensis was $19.07 \mu \mathrm{g} / \mathrm{mL}$, whereas Parvez et al. (2018) reported that the $\mathrm{IC}_{50}$ of ethanol extract for leaves of G. senegalensis was $82.7 \mu \mathrm{g} / \mathrm{mL}$. These results were higher than that obtained in this study $(10.21 \mu \mathrm{g} / \mathrm{mL})$.

Tannins isolated from the galls of G. senegalensis include gallic acid, epicatechin and galloylquinic acids, all of which have been shown to possess antioxidant activity (Bouchet, Barrier \& Fauconneau 1998). More recently, the presence of four antioxidant biomarkers: $\beta$-amyrin, $\beta$-sitosterol, lupeol and ursolic acid, was reported in the leaves of G. senegalensis (Parvez et al. 2018). Although 5-methyldihydroflavasperone has been 
extracted from the chloroform leaf extract of the plant (El Hadi \& Khalid 1997), the authors are not aware of any determination of antioxidant activity of the compound. In this study, the compound was isolated from the dichloromethane subfraction of the ethanol extract of the leaves. A very weak antioxidant potential was observed when compared with the antioxidant standard and the subfractions $(4 / 7 / 5)$. This suggests that the antioxidant activity observed is rather ascribed to other compounds and not to 5-methyldihydroflavasperone.

\section{Conclusion}

This is the first report on the isolation of 5-methyldihydroflavasperone from the ethanol leaf extracts of G. senegalensis. This compound was not found to be responsible for the observed antioxidant activity. Further research is warranted to assess the compound responsible for the antioxidant activity.

\section{Acknowledgements}

The authors extend their sincere gratitude to the Pretoria University and CSIR, South Africa and Alneelain University, Sudan for their support, guidance and Sudan Ministry of Higher Education for provision of research visit to the first author. Also, the authors thanks Dr Yahiya Suleiman of the Medicinal and Aromatic Plants Research Institute, Sudan (MAPRI) for plant sample authentication.

\section{Competing interests}

The authors declare that they have no financial or personal relationships that may have inappropriately influenced them in writing this article.

\section{Authors' contributions}

M.E.O.A. and J.S. carried out the extraction and purification of plant samples. M.E.O.A. and E.S.Y. performed data collection, carried out the antioxidant testing of plant extracts, fractions and isolates, and writing the draft of this article. M.E.O.A. and G.F. designed the NMR method and analysed NMR spectroscopy results. M.E.O.A. and P.S. designed, performed and analysed UPLC-MS analysis results. V.S. verified the methodology and supervised the findings of this work. All authors discussed the results and contributed to the final manuscript.

\section{Funding information}

M.E.O.A. received funding from the Sudan Ministry of Higher Education in the form of a scholarship to undertake this study.

\section{Data availability}

Data will be made available upon request from the corresponding author.

\section{Disclaimer}

The views and opinions expressed in this article are those of the authors and do not necessarily reflect the official policy or position of any affiliated agency of the authors.

\section{References}

Adebayo, I.A., Gagman, H.A., Balogun, W.G., Adam, M.A.A., Abas, R., Hakeem, K.R et al., 2019, 'Detarium microcarpum, Guiera senegalensis, and Cassia siamea induce apoptosis and cell cycle arrest and inhibit metastasis on MCF7 breas cancer cells', Evidence-Based Complementary and Alternative Medicine 23, 6104574. https://doi.org/10.1155/2019/6104574

Atawodi, S.E. \& Onaolapo, G.S., 2010, 'Comparative in vitro antioxidant potentia of different parts of Ipomoea asarifolia, Roemer \& Schultes, Guiera senegalensis, JF Gmel and Anisopus mannii NE Brown', Brazilian Journa of Pharmaceutical Sciences 46(2), 245-250. https://doi.org/10.1590/S198482502010000200011

Ayoub, S.M. \& Kingston, G.I., 1984, 'Lariciresinol derivatives from Turrea nilotica and Monechma ciliatum', Journal of Natural Products 47(5), 875-876. https://doi. org/10.1021/np50035a023

Bouchet, N., Barrier, L. \& Fauconneau, B., 1998, 'Radical scavenging activity and antioxidant properties of tannins from Guiera senegalensis (Combretaceae)' Phytotherapy Research 12(3), 159-162. https://doi.org/10.1002/(SICl)10991573(199805)12:3<159::AID-PTR209>3.0.CO;2-C

Brand-Williams, W., Cuvelier, M.-E. \& Berset, C., 1995, 'Use of a free radical method to evaluate antioxidant activity', Food Science and Technology 28(1), 25-30. https:// doi.org/10.1016/S0023-6438(95)80008-5

Bucar, F., Resch, M., Bauer, R., Burits, M., Knauder, E. \& Schubert-Zsilavecz, M., 1998 '5-Methylflavasperone and rhamnetin from Guiera senegalensis and their antioxidative and 5-lipoxygenase inhibitory activity', Die Pharmazie 53(12), 875.

El Hadi, N.M. \& Khalid, S.A., 1997, '5-methyldihydroflavasperone, a dihydronaphthopyran from Guiera sengalensis', Phytochemistry 46(4), 793-794. https://doi.org/10.1016/ S0031-9422(97)00098-8

Fiot, J., Sanon, S., Azas, N., Mahiou, V., Jansen, O., Angenot, L. et al., 2006 'Phytochemical and pharmacological study of roots and leaves of Guiera senegalensis JF Gmel (Combretaceae)', Journal of Ethnopharmacology 106(2), 173-178. https://doi.org/10.1016/j.jep.2005.12.030

Gu, L., Wu, T. \& Wang, Z., 2009, 'TLC bioautography-guided isolation of antioxidants from fruit of Perilla frutescens var. acuta', Food Science and Technology 42(1), 131-136. https://doi.org/10.1016/j.lwt.2008.04.006

Ifijen, I., Mamza, A., Fasina, K., Omoruyi, J. \& Ikhuoria, E., 2019, 'Phytochemical analysis of Guiera senegalensis JF Gmel extract and its anti-plasmodial properties on Wistar albino mice via oral route', International Journal of Pharmacology, Phytochemistry and Ethnomedicine 13, 35-44. https://doi.org/10.18052/www. scipress.com/IJPPE.13.35

Li, F.S. \& Weng, J.K., 2017, 'Demystifying traditional herbal medicine with modern approach', Nature Plants 3(8), 1-7. https://doi.org/10.1038/nplants.2017.109

Mahmoud, E.H.N. \& Khalid, S.A., 1997, '5-Methyldihydroflavasperone, a dihydronaphthopyran from Guiera sengalensis', Phytochemistry 46(4), 793-794. https://doi.org/10.1016/S0031-9422(97)00098-8

Malami, I., Jagaba, N.M., Abubakar, I.B., Muhammad, A., Alhassan, A.M., Waziri, P.M et al., 2020, 'Integration of medicinal plants into the traditional system of medicine for the treatment of cancer in Sokoto State, Nigeria', Heliyon 6(9), e04830. https://doi.org/10.1016/j.heliyon.2020.e04830

Mariod, A., Matthäus, B. \& Hussein, I., 2006, 'Antioxidant activities of extracts from Combretum hartmannianum and Guiera senegalensis on the oxidative stability of sunflower oil', Emirates Journal of Food and Agriculture 18(2), 20-28. https://doi. org/10.9755/ejfa.v12i1.5136

Parvez, M.K., Alam, P., Arbab, A.H., Al-Dosari, M.S., Alhowiriny, T.A. \& Alqasoumi, S.I., 2018, 'Analysis of antioxidative and antiviral biomarkers $\beta$-amyrin, $\beta$-sitosterol, lupeol, ursolic acid in Guiera senegalensis leaves extract by validated HPTLC methods', Saudi Pharmaceutical Journal 26(5), 685-693. https://doi.org/10.1016/j. jsps.2018.02.022

Salihu, S.O. \& Usman, A.A., 2015, 'Antimicrobial and phytochemical study of the bioactive fractions of Guiera senegalensis from Alasan Tambuwal, Nigeria', Journal of Pharmacognosy and Phytochemistry 3(6), 106-111.

Silva, O. \& Gomes, E.T., 2003, 'Guieranone A, a naphthyl butenone from the leaves of Guiera senegalensis with antifungal activity', Journal of Natural Products 66(3), 447-449. https://doi.org/10.1021/np0204904

Somboro, A.A., Patel, K., Diallo, D., Sidibe, L., Chalchat, J.C., Figueredo, G. et al., 2011, 'An ethnobotanical and phytochemical study of the African medicinal plant Guiera senegalensis JF Gmel', Journal of Medicinal Plants Research 5(9), 1639-1651.

Yuan, H., Ma, Q., Ye, L. \& Piao, G., 2016, 'The traditional medicine and modern medicine from natural products', Molecules 21(5), 559. https://doi.org/10.3390/ molecules 21050559 